\title{
ORIGINAL ARTICLE CRIPTO and its signaling partner GRP78 drive the metastatic phenotype in human osteotropic prostate cancer
}

\author{
E Zoni $^{1,2}$, L Chen $^{3}$, S Karkampouna ${ }^{1,2}$, Z Granchi $^{4}$, El Verhoef ${ }^{5}$, F La Manna ${ }^{1,2}$, J Kelber $^{6}$, RCM Pelger $^{1}$, MD Henry $^{7}$, E Snaar-Jagalska $^{2}$, \\ GJLH van Leenders ${ }^{5}$, L Beimers ${ }^{8}$, P Kloen ${ }^{9}$, PC Gray ${ }^{10}, \mathrm{G}$ van der Pluijm ${ }^{1}$ and M Kruithof-de Julio ${ }^{1,2}$
}

CRIPTO (CR-1, TDGF1) is a cell surface/secreted oncoprotein actively involved in development and cancer. Here, we report that high expression of CRIPTO correlates with poor survival in stratified risk groups of prostate cancer (PCa) patients. CRIPTO and its signaling partner glucose-regulated protein 78 (GRP78) are highly expressed in PCa metastases and display higher levels in the metastatic $\mathrm{ALDH}^{\text {high }}$ sub-population of PC-3M-Pro4Luc2 PCa cells compared with non-metastatic ALDH ${ }^{\text {low }}$. Coculture of the osteotropic PC-3MPro4Luc2 PCa cells with differentiated primary human osteoblasts induced CRIPTO and GRP78 expression in cancer cells and increases the size of the ALDH ${ }^{\text {high }}$ sub-population. Additionally, CRIPTO or GRP78 knockdown decreases proliferation, migration, clonogenicity and the size of the metastasis-initiating ALDH high sub-population. CRIPTO knockdown reduces the invasion of PC-3MPro4Luc2 cells in zebrafish and inhibits bone metastasis in a preclinical mouse model. These results highlight a functional role for CRIPTO and GRP78 in PCa metastasis and suggest that targeting CRIPTO/GRP78 signaling may have significant therapeutic potential.

Oncogene (2017) 36, 4739-4749; doi:10.1038/onc.2017.87; published online 10 April 2017

\section{INTRODUCTION}

Prostate cancer $(\mathrm{PCa})$ is the second most common cancer in men worldwide. ${ }^{1}$ While current treatments of primary tumors are initially very effective, these beneficial responses are often followed by tumor recurrence and incurable bone metastases. Therefore, identifying molecular mediators of PCa relapse and metastasis will aid in the development of therapies for this deadly phase of the disease.

CRIPTO (TDGF1, CRIPTO-1) is a small, GPI-anchored/secreted fetal oncoprotein that has important roles in regulating stem cell differentiation, embryogenesis, tissue growth and remodeling. ${ }^{2}$ CRIPTO promotes transformation, migration, invasion and angiogenesis and its misregulation can contribute to cancer development and progression in multiple malignancies, including breast cancer and PCa, which are both characterized by osteotropism in their metastatic stage. ${ }^{3,4}$ CRIPTO modulates crucial pathways that regulate bone metastasis such as the tumor growth factor- $\beta$ (TGF- $\beta$ ) pathway ${ }^{5}$ and functions as an obligatory coreceptor for Nodal, a TGF- $\beta$ superfamily member that promotes epithelial-tomesenchymal transition (EMT) in $\mathrm{PCa}{ }^{5-7}$ Glucose-regulated protein 78 (GRP78) was identified as a CRIPTO-binding protein and essential mediator of CRIPTO signaling. ${ }^{8-10}$ GRP78 is well established as a key survival factor in development and cancer ${ }^{8,9}$ and, notably, upregulation of GRP78 has been associated with the development of castration-resistant PCa. ${ }^{11}$ While CRIPTO was reported to impact primary human prostate adenocarcinomas, ${ }^{6}$ its role in driving castration-resistant PCa and PCa bone metastasis remains unknown.
Here, we investigated the roles of CRIPTO and GRP78 in aggressive, metastatic human PCa cells both in vitro and in vivo using an embryonic zebrafish model and a preclinical mouse model of experimentally induced PCa bone metastasis. We found that CRIPTO and GRP78 are upregulated in clinical samples of PCa metastases from human patients and in the highly metastatic $\mathrm{ALDH}^{\text {high }}$ stem/progenitor-like sub-population of a human castration-resistant PCa cell line. ${ }^{12,13}$ We further demonstrate that knockdown of CRIPTO or GRP78 in these cells decreases the size of the stem/progenitor-like sub-population and also inhibits their extravasation following inoculation into zebrafish and their metastatic potential in a preclinical mouse model of bone metastasis in vivo. Taken together, these findings provide new evidence that CRIPTO and GRP78 may drive metastatic PCa and highlight the therapeutic potential of targeting the cell surface CRIPTO/GRP78 complex for the treatment of this deadly disease.

\section{RESULTS}

CRIPTO is highly expressed in metastases from human PCa patients and correlates with poor survival

CRIPTO and its signaling partner GRP78 have been shown to have important roles in tumor development and bone metastasis. ${ }^{14} \mathrm{We}$ investigated the correlation of survival with CRIPTO expression in independent sets of public PCa data sets (GSE21032 and GSE $10645^{15,16}$ ). In both data sets, CRIPTO expression was associated with poor prognosis (Figures 1a and b (top); hazard ratio $(\mathrm{HR})=1.87$ and $P=0.001$ for GSE10645 and $\mathrm{HR}=2.2$ and

\footnotetext{
${ }^{1}$ Department of Urology, Leiden University Medical Centre, Leiden, The Netherlands; ${ }^{2}$ Urology Research Laboratory, Department of Urology and Department of Clinical Research, University of Bern, Bern, Switzerland; ${ }^{3}$ Department of Molecular Cell Biology, Institute of Biology, Leiden University, Leiden, The Netherlands; ${ }^{4}$ Genome Scan, Leiden, The Netherlands; ${ }^{5}$ Department of Pathology, Erasmus MC, Rotterdam, The Netherlands; ${ }^{6}$ Department of Biology, California State University Northbridge, Northbridge, CA, USA; ${ }^{7}$ Department of Molecular Physiology and Biophysics, University of lowa, lowa City, IA, USA; ${ }^{8}$ Department of Orthopedic Surgery, Slotervaart Medical Center, Amsterdam, The Netherlands; ${ }^{9}$ Department of Orthopedic Trauma Surgery, Academic Medical Center, Amsterdam, The Netherlands and ${ }^{10}$ Clayton Foundation Laboratories for Peptide Biology, The Salk Institute for Biological Studies, La Jolla CA, USA. Correspondence: Dr M Kruithof-de Julio, Urology Research Laboratory, Department of Urology and Department of Clinical Research, University of Bern, Murtenstrasse 35, Bern 3008, Switzerland.
}

E-mail: marianna.kruithofdejulio@dkf.unibe.ch

Received 5 July 2016; revised 10 February 2017; accepted 26 February 2017; published online 10 April 2017 
4740

$P=0.06$ for GSE21032). Additionally, in both data sets, the expression of CRIPTO in stratified risk groups was significantly higher in the high- vs low-risk group (Figures 1a and b (bottom);

a Cripto Expression - Kollemeyer - Jenkins Prostate
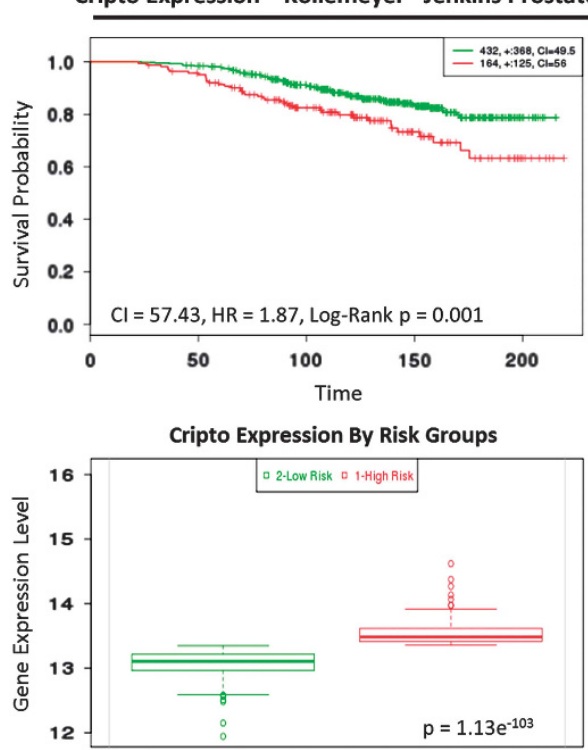

C

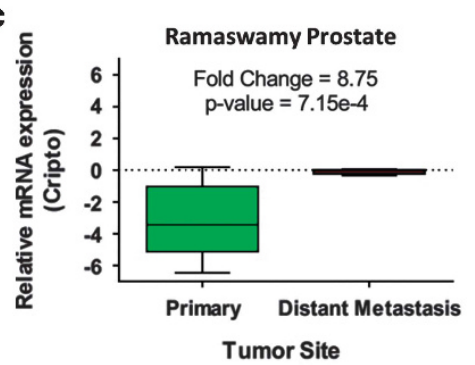

d

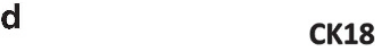

흥
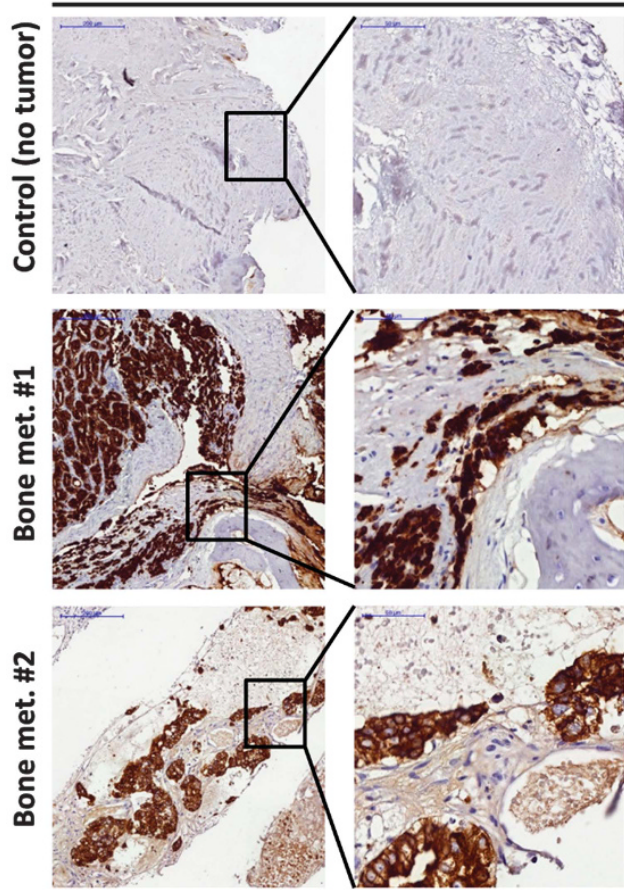

$P=1.13 e-103$ for GSE10645 and $P=3.68$ e -23 for GSE21032).

We further investigated the expression of CRIPTO and GRP78

in the Ramaswamy Multi-cancer data set from Oncomine

b
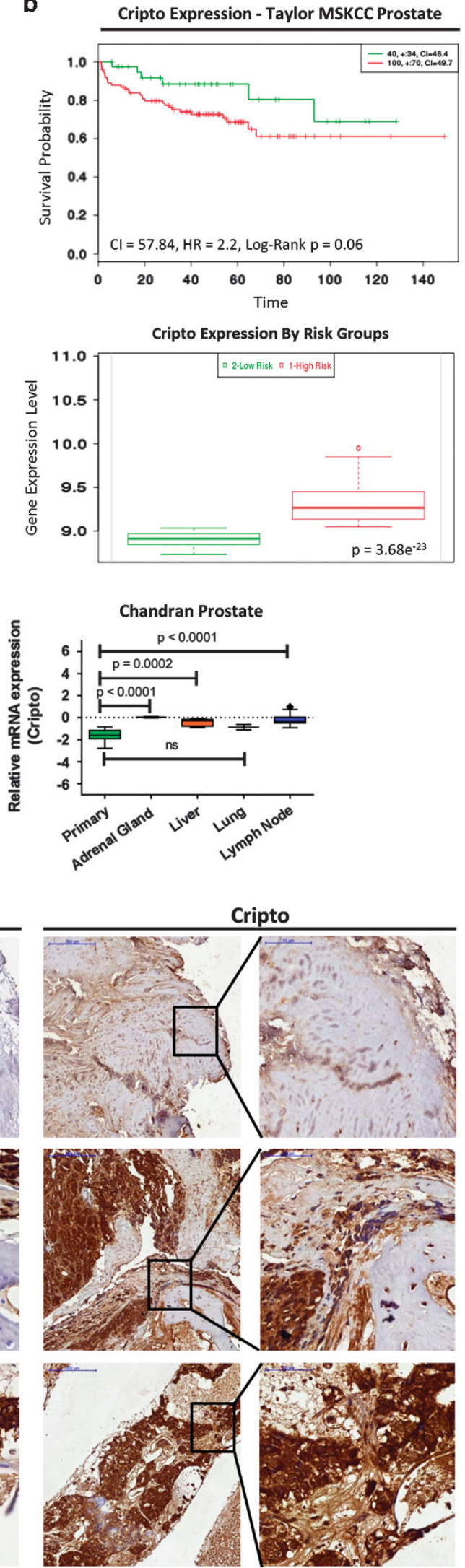
(Compendia Bioscience, Waltham, MA, USA), which compares PCa metastasis to primary sites in 76 samples $^{17}$ and includes quantified differential gene expression patterns between human primary tumors and metastatic lesions arising from corresponding primary site. Additionally, to investigate the levels of CRIPTO in site-specific metastases, we also analyzed a previously published data set (Chandran prostate GSE6752) where 31 prostate specimens (10 primary and 21 hormone-refractory metastatic) were included. ${ }^{18}$ We found that CRIPTO and GRP78 are significantly upregulated in metastatic lesions arising from human prostate tumors, compared with primary sites in human PCa (Figures 1C, $P=7.15 \mathrm{e}-4$ for CRIPTO and $P=0.03$ for GRP78; Supplementary Figures $1 \mathrm{~A}$ and $\mathrm{B})$. Subsequently, we investigated the expression of CRIPTO in PCa bone metastases by immunostaining of paraffinembedded sections of bone metastases freshly isolated from patients. We detected significant expression of CRIPTO and colocalization of CRIPTO with cytokeratin-18 in serial sections from each of the 13 specimens analyzed (Figure 1d). Taken together, these data demonstrate that CRIPTO is selectively expressed in aggressive and metastatic PCa and that its expression correlates with poor prognosis.

Coculture with primary human osteoblasts augments the ALDH ${ }^{\text {high }}$ sub-population, upregulates CRIPTO and GRP78 and promotes the metastatic phenotype of PCa cells

We previously reported that the $\mathrm{ALDH}^{\text {high }}$ sub-population of PC-3M-Pro4Luc2 cells displays stem/progenitor-like properties and is highly metastatic relative to its ALDH $^{\text {low }}$ counterpart. ${ }^{12}$ CRIPTO and GRP78 are expressed in human PCa cell lines (PC-3MPro4Luc2 and C4-2B cells) (Figures $2 \mathrm{a}-\mathrm{C}$ ) and given their known roles in regulating tumor aggressiveness, we tested if CRIPTO and GRP78 are selectively expressed in the ALDH ${ }^{\text {high }}$ sub-population. Quantitative real-time PCR (qRT-PCR) (Figure $2 \mathrm{~d}$ ) and protein analysis (Figures $2 e$ and $f$ ) on selected sub-population of cells isolated after viable cell sorting showed that GRP78 levels were indistinguishable in both sub-populations but that CRIPTO was more highly expressed in the ALDH ${ }^{\text {high }}$ sub-population than in the ALDH $^{\text {low }}(P<0.01$ for CRIPTO). This result is consistent with a role for CRIPTO in promoting PCa growth and metastasis.

In PCa and other cancers, the osteoblastic microenvironment functions as premetastatic niche by attracting bone-metastasizing tumor cells. ${ }^{19-21}$ We developed a model of the bone metastatic niche in which primary human osteoblasts are cocultured with PC-3M-Pro4Luc2 cells in vitro. Differentiation of the human osteoblasts was confirmed by Alizarin red staining (Supplementary Figure 2A). We found that in the presence of osteoblasts, the size of the $\mathrm{ALDH}^{\text {high }}$ sub-population increases markedly compared with the size of the ALDH ${ }^{\text {high }}$ sub-population in PCa cells alone (coculture $=60$ vs control $=15 \%, P<0.05$ ) (Figure 2g). This effect appeared to be osteoblast-specific as coculture of PCa cells with a non-osteoblast cell line (HEK293T cells) failed to reproduce the significant increase in the percentage of ALDH ${ }^{\text {high }}$ cells (Supplementary Figure 2b). Moreover, mRNA analysis after viable cell sorting of fluorescently labeled PC-3M-Pro4Luc2 cells (cocultured cells compared with control) showed significant increase in CRIPTO $(P<0.05)$ and GRP78 expression (Figure $2 \mathrm{~h}$ ). In addition, conditioned medium (CM) generated in the absence of serum, collected from osteoblasts, increased the migratory capability of PC-3MPro4Luc2 cells and the increase was directly proportional to the concentration of the CM used $(P<0.001$ for $50 \mathrm{CM}+50 \%$ not-CM vs control; $P<0.001$ for $100 \% \mathrm{CM}$ vs control and $P<0.001$ for $100 \mathrm{CM}$ vs $50 \%$ CM; Figure $2 \mathrm{i})$. In line with these observations, administration of osteoblast CM led to the acquisition of a motile, mesenchymal phenotype in PC-3M-Pro4Luc2 PCa cells as indicated by a decrease in the mRNA expression of the epithelial marker E-cadherin $(P<0.05)$, a concomitant increase in the mesenchymal markers ZEB1 and ZEB2 ( $P<0.05$ for both genes) (Supplementary Figure $2 \mathrm{C}$ ) and a significant reduction of the ratio E-cadherin/vimentin $(P<0.05)$ and ratio $\mathrm{E}$-cadherin/ $\mathrm{N}$-cadherin (Figure 2j). Taken together, these data indicate that secreted factors derived from osteoblasts promote the metastatic phenotype of PCa cells and increases their expression of CRIPTO and GRP78.

\section{CRIPTO and GRP78 maintain aggressiveness of human PCa cells} in vitro

To test the function of CRIPTO and GRP78 in human PCa cells, we generated stable knockdown lines in PC-3M-Pro4Luc2 and C4-2B cells and validated reduced expression of CRIPTO and GRP78 by qRT-PCR, western blot and FACS analysis (Figures $3 a$ and $b$ and Supplementary Figures $3 \mathrm{~A}-\mathrm{E}$ ). As previously shown by others in PC3 cells and consistent with the extensive post-translational modification of CRIPTO, we detected two protein bands of $\sim 17$ and $25 \mathrm{kDa}^{5,22}$ (Figure 3b). CRIPTO knockdown lines (short hairpin RNA (shRNA) no. 2 and 3 ) both show decreased cell proliferation $(P<0.001$ at $24 \mathrm{~h}$ for shRNA no. 2 and $P<0.001$ at 24,48 and $72 \mathrm{~h}$ for shRNA no. 2 and 3) (Figure 3c). We confirmed the acquisition of this phenotype upon CRIPTO silencing by an additional pool of independent siRNAs targeting CRIPTO (Supplementary Figures 3F and $3 G$ ). No effect on cell proliferation was observed in the C4-2B CRIPTO knockdown cells (Supplementary Figure 4A). The PC-3MPro4Luc2 CRIPTO knockdown cells also had a significantly reduced percentage of metastatic, stem cell-like ALDH ${ }^{\text {high }}$ cells relative to non-targeted (NT) control cells $(P<0.05$ for shRNA no. 2 and $P=$ NS for shRNA no. 3; Figure 3d). GRP78 knockdown similarly displayed reduction of the size of $A L D H^{\text {high }}$ sub-population of cells $(P<0.05$ for shRNA no. 1 and $P=$ NS for shRNA no. 2) (Supplementary Figure 4B).

We previously reported that the ALDH ${ }^{\text {high }}$ sub-population of PC-3M-Pro4Luc2 is enriched for cells with increased clonogenicity and migratory properties relative to the $\mathrm{ALDH}^{\text {low }}$ cells. ${ }^{12}$ Consistent with our ALDEFLUOR data, we show that PC-3M-Pro4Luc2 CRIPTO knockdown with shRNA no. 2 significantly reduces clonogenicity, as measured by the number and area of colonies produced $(P<0.05) \quad$ (Supplementary Figure 4C). This effect appeared to be specific since transfection of a non-targetable mouse CRIPTO expression construct resulted in significant rescue of the loss of clonogenicity caused by the CRIPTO shRNA $(P<0.001$ for colony number and $P<0.05$ for colony area) (Figure 3e). GRP78 knockdown in PC-3M-Pro4Luc2 human PCa cells also resulted in a decrease in the number of colonies $(P<0.05)$ and a similar trend was shown for colony area (Supplementary Figure 4D). Finally, CRIPTO knockdown significantly reduced the migratory capability of both cell lines $(P<0.05$ and $P<0.01$ respectively; Figures $4 \mathrm{a}$ and $\mathrm{b})$, these findings were

Figure 1. CRIPTO is expressed in PCa metastasis from human patients and correlates with poor patient prognosis. (a and b) Top panels: Kaplan-Meier survival curves of censored Cox analysis in Kollemeyer-Jenkins prostate and Taylor-MSKCC prostate database stratified by maximized CRIPTO expression risk groups. Red = high expression; green =low expression. Bottom panels: CRIPTO expression stratified by risk groups. Red = high-risk and high CRIPTO expression; green = low-risk and low CRIPTO expression. Data accessed from http://bioinformatica. mty.itesm.mx:8080/Biomatec/SurvivaX.jsp. (c) CRIPTO is significantly upregulated in PCa metastasis. The Ramaswamy Multi-cancer publicly available data set and the Chandran data set (data accessed from www.oncomine.org) was used for analysis. Data are represented in Tukey's plot format for each individual patient, respectively. (d) Representative images of serial sections of PCa bone metastasis stained for cytokeratin-18 (CK18) and CRIPTO and counter stained with hematoxylin $(N=13)$ at lower $(\times 10)$ and higher $(\times 40$, see inserts) magnification. 
a

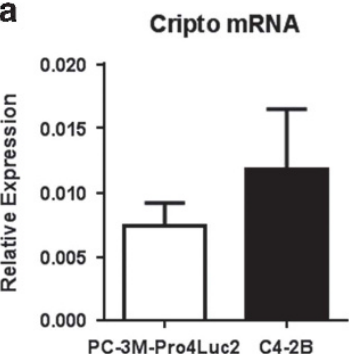

d

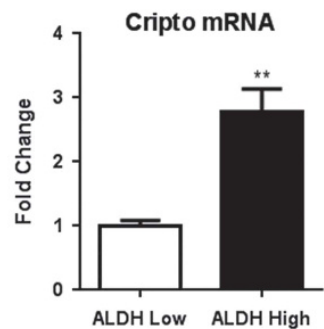

GRP78 mRNA
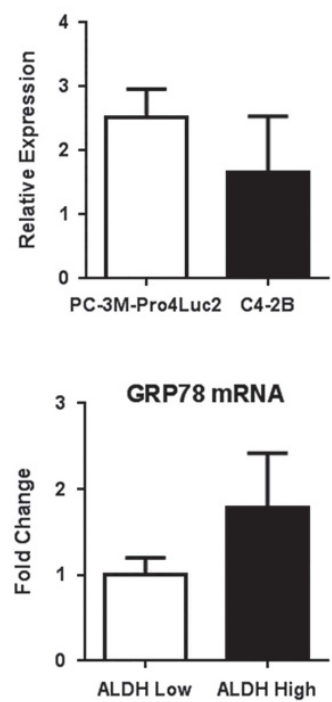

b

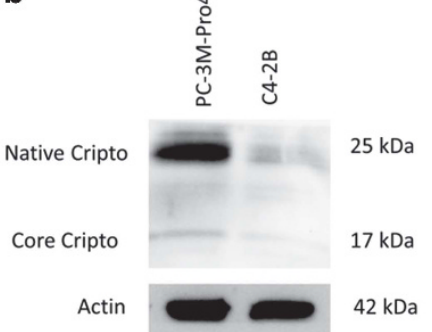

e

Native Cripto

Core Cripto

Actin

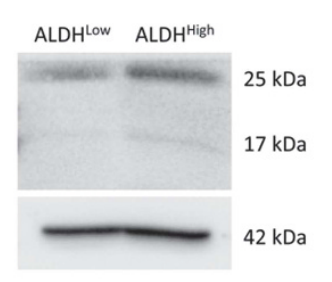

g

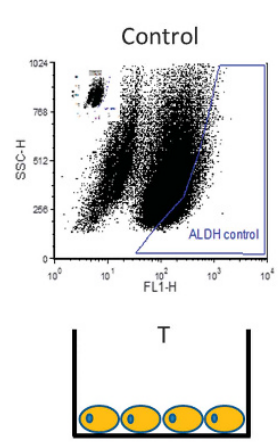

i

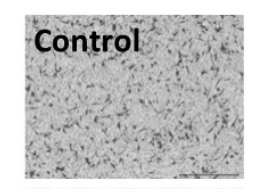

Direct co-culture
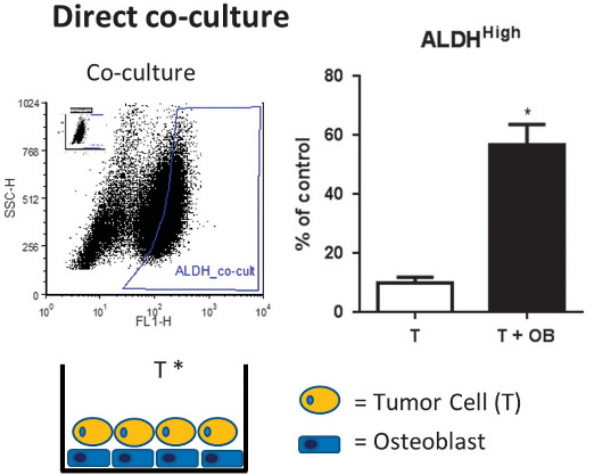

- Tumor Cell (T) h
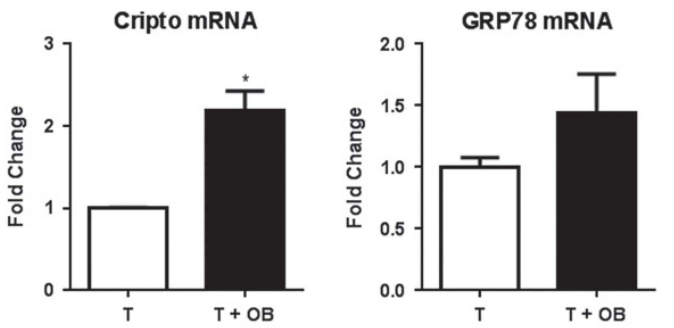

j

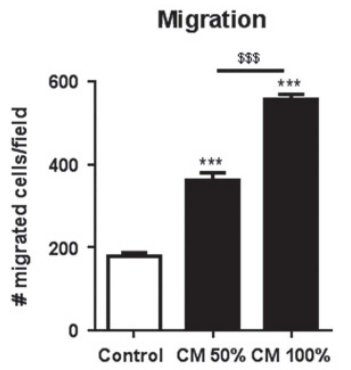

Control $\mathrm{CM} 50 \%$ CM $100 \%$
E-Cad/N-Cad

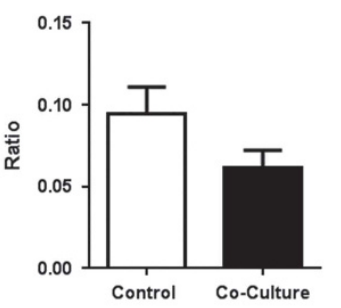

$\mathbf{f}$
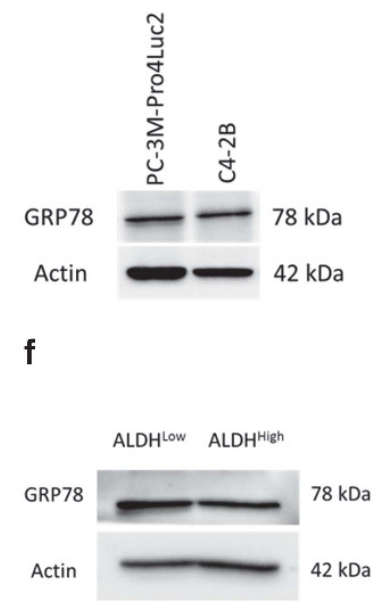
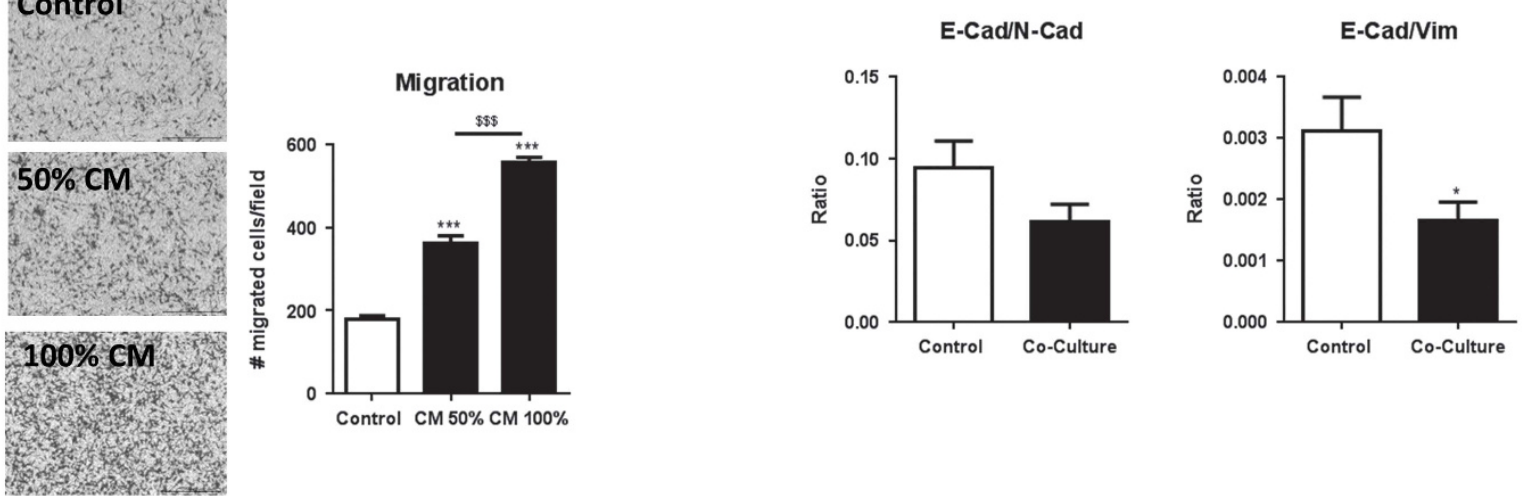

Figure 2. Coculture with human osteoblasts (OBs) increases expression of CRIPTO and GRP78 and stem cell-like properties of human PCa cells. (a-c) CRIPTO and GRP78 expression in PC-3M-Pro4Luc2 and C4-2B human PCa cell lines. Error bars \pm s.e.m. (d) CRIPTO and GRP78 expression in highly metastatic sub-population of ALDH high PCa cells vs low metastatic ALDH ${ }^{\text {low }}$ in PC-3M-Pro4Luc2 cells. Error bars \pm s.e.m. (e and f) CRIPTO but not GRP78 protein is increased in highly metastatic sub-population of ALDH ${ }^{\text {high }}$ PCa cells vs low metastatic ALDH ${ }^{\text {low }}$ in PC-3M-Pro4Luc2 cells isolated after viable cell sorting. (g) Direct coculture of fluorescently labeled PC-3M-Pro4Luc2 human PCa cells (T; 900000 cells seeded per petri dish) with differentiated human OBs (confluent layer of differentiated cells per petri dish) for $48 \mathrm{~h}$ increases the size of the ALDH $\mathrm{H}^{\text {high }}$ subpopulation in PCa cells. Each samples is gated according to its internal control (small panel represented in the top left part of the plot). Error bars \pm s.e.m. Two experiments are shown. Assay replicated more than three times in the laboratory. (h) mRNA analysis shows increased CRIPTO and GRP78 expression after coculture. Error bars \pm s.e.m. Two experiments are shown. Assay replicated more than three times in the laboratory. (i) CM from human osteoblast, generated in the absence of serum, enhances migration of PC-3M-Pro4Luc2 human PCa cells. Error bars \pm s.e.m. Two experiments are shown. Assay replicated three times in the laboratory. (j) Coculture of PC-3M-Pro4Luc2_dTomato PCa cells for 48 $\mathrm{h}$ with human osteoblast induces a shift to mesenchymal phenotype (decrease in ratio E-cadherin/vimentin and E-cadherin/ $\mathrm{N}$-cadherin). Error bars \pm s.e.m. Two experiments are shown, assay replicated more than three times in the laboratory. ${ }^{*} P<0.05,{ }^{* *} P<0.01,{ }^{* * *}$ and ${ }^{\$ \$} P<0.001$. 
a

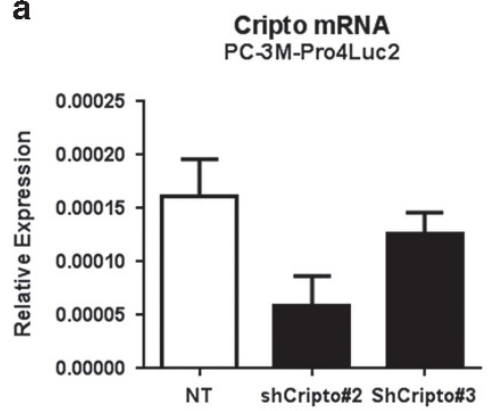

b
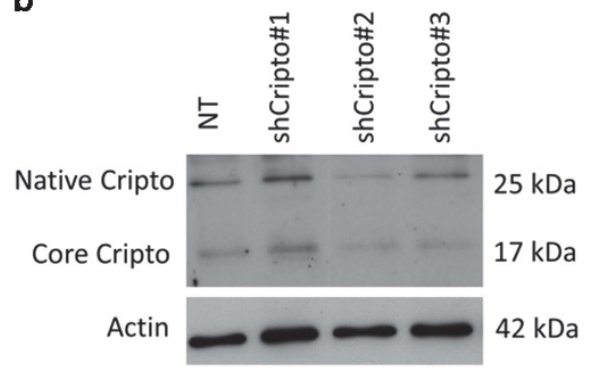

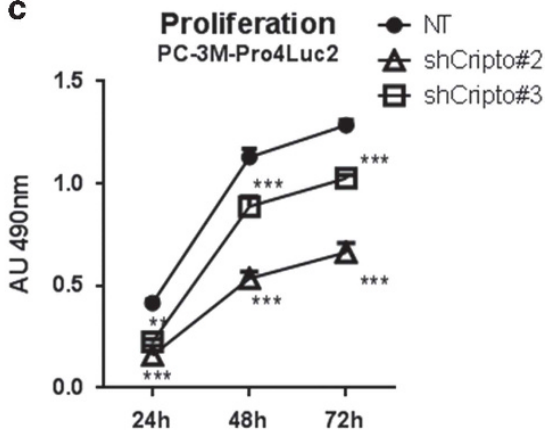

d
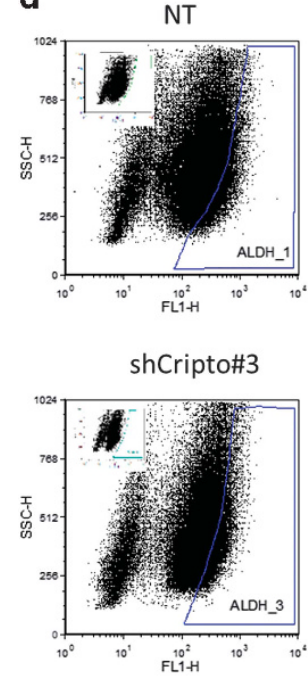

shCripto\#2

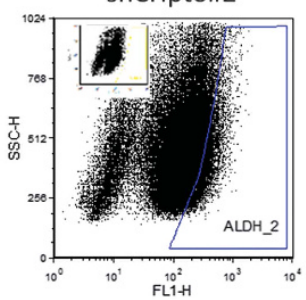

ALDEFLUOR

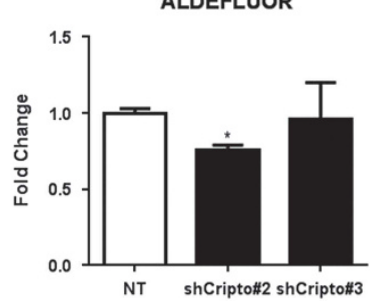

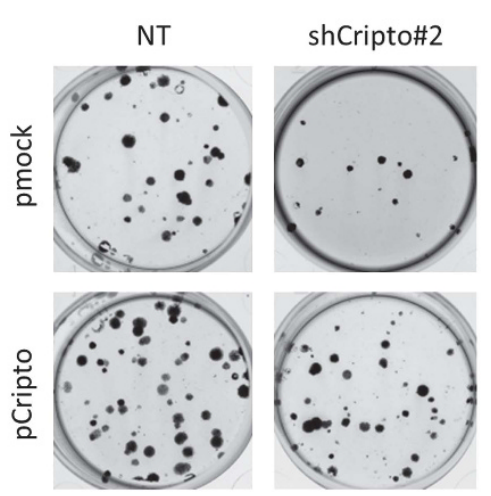
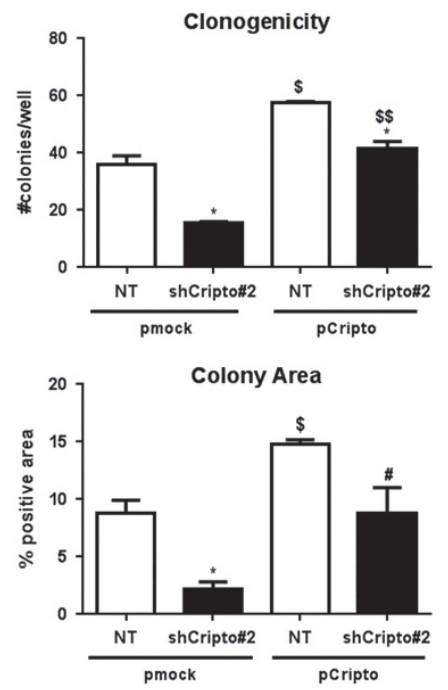

Figure 3. CRIPTO knockdown causes loss of the stem cell-like phenotype in PCa cells. (a and b) qRT-PCR and Western blot analysis of CRIPTO expression in control (scrambled shRNA, NT) PC-3M-Pro4Luc2 (first lane) and CRIPTO knockdown PC-3M-Pro4Luc2 cells with shCRIPTO no. 1-3, derived from different shRNA constructs. Two bands of, respectively, $25 \mathrm{kDa}$ (Native) and $17 \mathrm{kDa}$ (Core) for CRIPTO are detected as shown previously (see Results). (c) Knockdown of CRIPTO affects the proliferation in PC-3M-Pro4Luc2. Error Bars \pm s.e.m. (d) CRIPTO knockdown leads to a decrease in the size of ALDH ${ }^{\text {high }}$ sub-population in PC-3M-Pro4Luc2 cells. Error Bars \pm s.e.m. (e) CRIPTO knockdown affects clonogenic ability and CRIPTO overexpression is capable of reversing this phenotype in PC-3M-Pro4Luc2. Error bars \pm s.e.m. ${ }^{*, \$, \#} P<0.05 ;{ }^{* *, \$ \$} P<0.01$; $* * * P<0.001$

confirmed by an independent pool of siRNAs (Supplementary Figure 4E). Significant rescue of the effects of shRNA knockdown could be again achieved by the non-targetable CRIPTO expression construct solely in PC-3M-Pro4Luc2 cells (Figures 4c and d). GRP78 knockdown in PC-3M-Pro4Luc2 cells also resulted in a significant reduction of migratory potential $(P<0.001$ for both shRNAs) (Supplementary Figure 4F). Additionally, CRIPTO knockdown in PC-3M-Pro4Luc2 cells significantly reduced the migration towards osteoblast CM (Supplementary Figures $5 \mathrm{~A}$ and B). Taken together, these data suggest that CRIPTO and GRP78 are required to maintain an aggressive phenotype of PC-3M-Pro4Luc2 cells.

CRIPTO promotes EMT and invasiveness of human PCa cells

EMT is strongly associated with tumor cell invasion and CRIPTO was recently reported to promote EMT in human PCa. ${ }^{6}$ Consistent with this study, we found that CRIPTO overexpression in PC-3MPro4Luc2 and C4-2B cells (Supplementary Figures $6 \mathrm{~A}$ and $\mathrm{B}$ ) causes a strong and significant downregulation of the epithelial marker E-cadherin $(P<0.05)$ at the mRNA level in both cell lines and an increase in the mesenchymal markers vimentin, SNAIL2 and TWIST in PC-3M-Pro4Luc2 cells $(P<0.05, P<0.05$ and $P<0.01$, respectively) and ZEB1 in C4-2B cells (Supplementary Figures $6 \mathrm{c}$ and d). CRIPTO overexpression caused a strong and significant decrease in the ratio of E-cadherin/vimentin $(P<0.01)$ in both PCa cell lines (Figures $4 e$ and f). Taken together, these data support a role for CRIPTO in promoting EMT and the invasive phenotype in PC-3M-Pro4Luc2 and C4-2B cells. Additionally, and consistent with previous reports, ${ }^{8,23}$ we have found that CRIPTO modulates TGF- $\beta$ signaling in our model system (Supplementary Figure $6 \mathrm{E}$ ). These data are consistent with previous reports documenting extensive interaction of CRIPTO with the TGF- $\beta$ pathway and other signaling networks. ${ }^{24,25}$

We have previously shown that zebrafish can be used to evaluate effectively migration and invasion of human PCa cells and the interaction between PCa cells and the vasculature at the single-cell level in vivo. ${ }^{13,26}$ Clear detection of extravasating tumor cells in this system is facilitated by the fact that the vascular system of zebrafish embryos is completely functional and the embryos are transparent. ${ }^{27}$ We tested the role of CRIPTO and GRP78 in PCa cell extravasation and metastasis by injecting fluorescently labeled PC-3M-Pro4Luc2 cells with CRIPTO or GRP78 knocked down into the circulatory system of zebrafish embryos. ${ }^{13}$ In the first hours, disseminated cells arrested in the host vasculature and then we observed extravasation from $12 \mathrm{hpi}$ (hours postimplantation) and perivascular tumor cells in multiple foci including the intersegmental vessels, the optic veins, the dorsal aorta and the caudal vein. The perivascular tumor cells invaded the neighboring tail fin exclusively at the posterior ventral end of the hematopoietic tissue. At day 4 postimplantation ( $4 \mathrm{dpi}$ ), CRIPTO knockdown caused a significant reduction in extravasation 
a
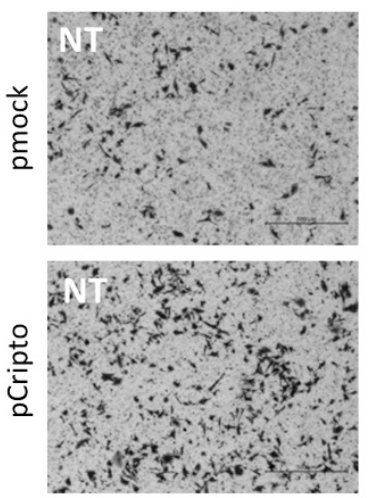

C

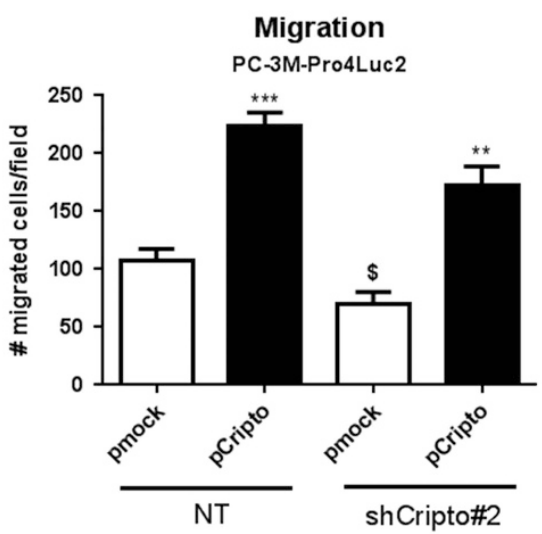

e

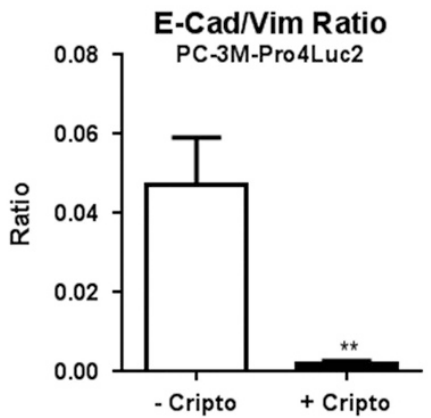

b
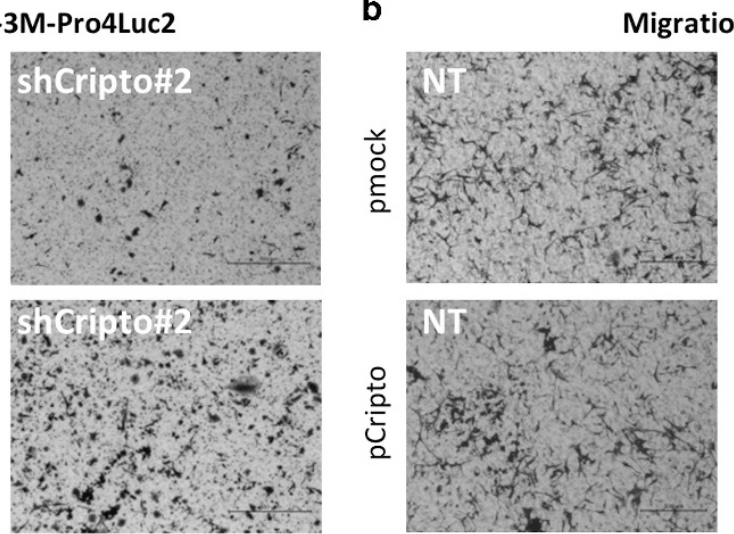

d

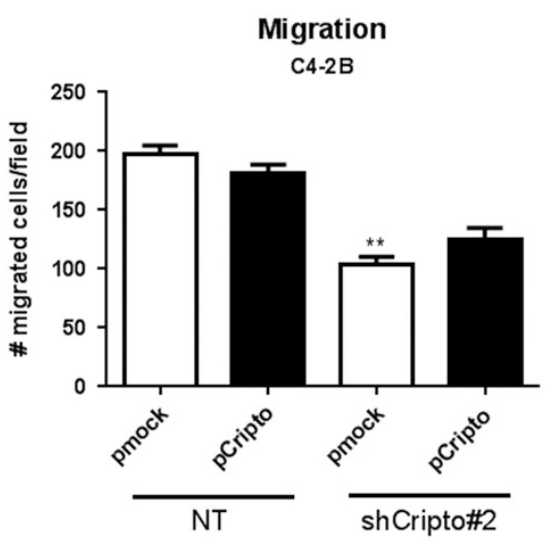

f

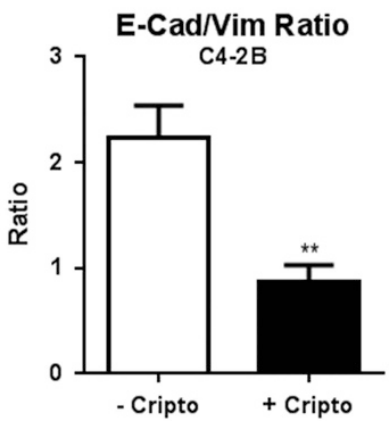

Figure 4. CRIPTO overexpression promotes PCa cell migration and rescues effects of CRIPTO knockdown. (a and b) CRIPTO Knockdown significantly reduces cell migration in PC-3M-Pro4Luc2 and C4-2B cells and CRIPTO overexpression is capable of rescuing completely (PC-3MPro4Luc2) or partially (C4-2B) the phenotype. Quantification is shown in (c and d) Error bars \pm s.e.m. (e) mRNA analysis in PC-3M-Pro4Luc2 cells and C4-2B (f) after $48 \mathrm{~h}$ of CRIPTO overexpression shows decrease in E-cadherin/vimentin ratio. Error bars \pm s.e.m. ${ }^{\$} P<0.05,{ }^{* *} P<0.01$ and ${ }^{* * *} P<0.001$.

and tumor growth compared with control cells with scrambled shRNA (Figures 5a-c). Similarly, GRP78 knockdown cells displayed a significant reduction in the tumor growth into the tail fin after invasion from hematopoietic tissue compared to control cells (Supplementary Figures 7A and B). However, invasion was not significantly different in GRP78 knockdown cells compared with control cells (Supplementary Figure 7C). Taken together, these data support our in vitro findings and reinforce the hypothesis that CRIPTO/GRP78 signaling has an important role in the maintenance of an invasive and aggressive phenotype in human PCa.

CRIPTO knockdown decreases metastasis formation in preclinical mouse model of PCa bone metastasis

We previously demonstrated that intracardiac injection of luciferase-expressing PC-3M-Pro4Luc2 cells in mice results in bone metastasis. ${ }^{12}$ Here, we used this preclinical mouse model to test the role of CRIPTO in mediating the metastatic activity of these PCa cells. CRIPTO knockdown cells or control cells with a scrambled shRNA were injected into the left cardiac ventricle of nude mice (Balb/c nu/nu) and bioluminescence, which reflects tumor size, was measured weekly for the course of the experiment. The same batch of cells injected was functionally tested in vitro (Supplementary Figure 8A). Quantification of bioluminescent images (Figures $6 a$ and $b$, week $5, P<0.05$ ) showed significant reduction in metastasis formation and the total number of metastases (Figure $6 c$, week $5, P<0.01$ ), specifically bone metastases (Figure $6 \mathrm{~d}$, week $5, P<0.01$ ), in mice inoculated with CRIPTO knockdown cells compared with mice injected with control cells. No effect on weight of the animals was measured (Supplementary Figure 8B). This result is consistent with the other findings outlined above and suggests that CRIPTO is required for bone metastasis in a mouse model of human PCa. 
a
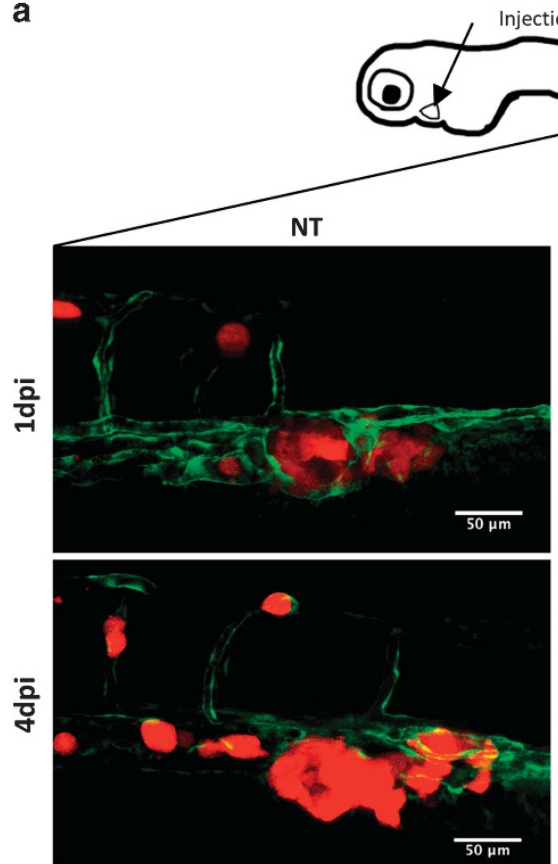

b

Whole-body tumor burden

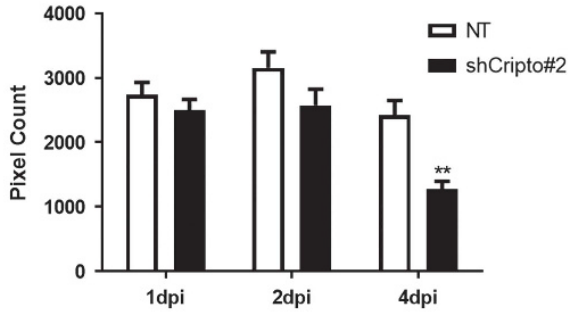

C
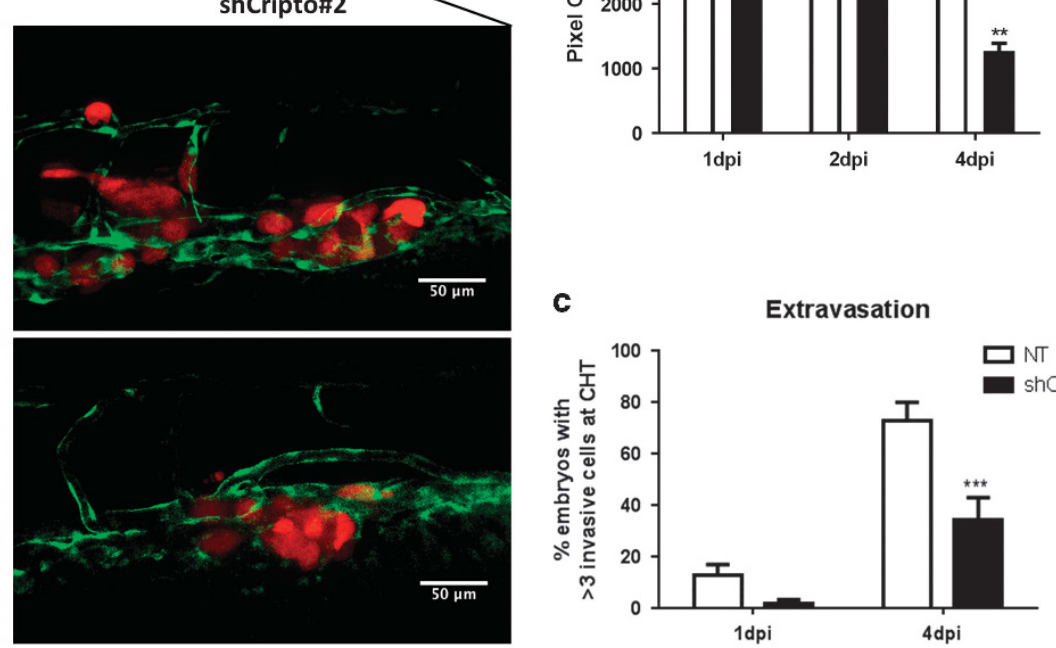

Figure 5. CRIPTO knockdown reduces invasion and tumor growth of human PCa cells in vivo. (a) PC-3M-Pro4Luc2_dTomato human PCa cells with scrambled shRNA control (NT) and shCRIPTO no. 2 shRNAs were injected into the duct of Cuvier to monitor extravasation and formation of distant growth in vivo (30 embryos injected per group). (b) CRIPTO knockdown reduces whole-body tumor burden at 4 dpi (days post injection). Error bars \pm s.e.m. (c) CRIPTO knockdown reduces the number of extravasated cells at 1 and 4 dpi at the caudal hematopoietic tissue. Error bars \pm s.e.m. ${ }^{* *} P<0.01$ and ${ }^{* *} P<0.001$.

\section{DISCUSSION}

This study presents evidence for a role of CRIPTO and GRP78 in the regulation of the invasive program of $\mathrm{PCa}$ cells that maintains stem cell-like and aggressive phenotypes in human PCa. Our demonstration that CRIPTO is strongly upregulated in high-risk patient groups compared with low-risk groups and that it correlates with poor survival highlight the significance of these proteins in metastatic PCa. Importantly, the selective expression of CRIPTO and GRP78 in PCa metastases was substantiated by the analysis of publicly available data sets ${ }^{17,18}$ and reinforced by our analysis on 13 samples of PCa bone metastasis derived from castration-resistant $\mathrm{PCa}$ patients.

CRIPTO/GRP78 signaling is known to regulate stem cells and tumor cells $\mathrm{s}^{25}$ and our results suggest that this signaling may promote the acquisition of a metastatic phenotype in PCa. This phenotype includes the ability of PCa cells to invade the supportive stroma and neighboring tissues to allow subsequent formation of bone metastases at distant sites. ${ }^{28}$ CRIPTO/GRP78 signaling may also have a specific role in metastasis by facilitating initial colonization of the bone by PCa cells. Remarkably, we also observe a decline in the number of bone foci in the first 10-15 days of the mouse metastasis experiments, followed by much stronger growth of control tumor cells in the bone relative to the CRIPTO knockdown cells. These data are in line with our previous study, which shows a similar kinetic ${ }^{29}$ and support the hypothesis that only a small percentage of prostate cancer cells possess the ability to reach efficiently the bone, survive in the bone microenvironment and establish a new growth. Our data further suggest that this sub-population of PCa cells has stem/ progenitor-like properties that depend on CRIPTO expression. ${ }^{30}$

The ALDH ${ }^{\text {high }}$ sub-population of PC-3M-Pro4Luc2 cells is enriched for tumor-initiating cells with metastatic potential and generally accounts for a small percentage of all tumor cells. ${ }^{12,13}$ Here, we show that these highly metastatic ALDH ${ }^{\text {high }}$ cells have higher levels of CRIPTO protein expression compared with non-stem cell-like, non-metastatic ALDH ${ }^{\text {low }}$ cells. This finding supports our hypothesis that CRIPTO is restricted to a small subpopulation of cells characterized by high metastatic ability, similar to what was recently shown in breast cancer. ${ }^{31}$ Our results also support the notion that CRIPTO signaling promotes $\mathrm{EMT}^{6,7}$ and the migratory and invasive phenotype in PCa cells associated with a switch from a sessile, epithelial state to a motile, mesenchymal phenotype. Indeed, transcriptional analysis following CRIPTO overexpression reveals the emergence of an 'EMT signature' characterized by a marked reduction in the expression of the epithelial marker E-cadherin paralleled by a significant increase in the expression of the mesenchymal markers vimentin, Snail2 and Twist.

The activation of the bone stroma by metastatic cells alters the physiological balance between osteoblast-mediated bone formation and osteoclast-mediated bone resorption during bone metastatic colonization. ${ }^{32}$ Strikingly, we found that coculture of PCa cells with human osteoblasts, which are important cellular constituents of the bone metastatic niche, ${ }^{32}$ induced a significant increase in CRIPTO and GRP78 mRNA expression in the tumor cells. Osteoblasts have previously been reported to promote the aggressiveness of osteolytic human PCa cells in vitro. ${ }^{19}$ These findings are in line with our data showing that osteoblasts promote the metastatic phenotype of PCa cells by causing expansion of the ALDH ${ }^{\text {high }}$ sub-population, increasing tumor cell migration and inducing expression of CRIPTO and GRP78. In light of previous studies demonstrating that CRIPTO binds cell surface GRP78 and that this interaction is required for CRIPTO signaling, our results suggest that CRIPTO and GRP78 function cooperatively to regulate the interaction between tumor cells and osteoblasts within the bone microenvironment. However, given the complexity of the bone metastatic niche, we focused primarily on the role of CRIPTO and GRP78 in the maintenance of an aggressive and metastatic phenotype in PCa cells. Additional experiments are required to elucidate the interactions between $\mathrm{PCa}$ cells and the 
a

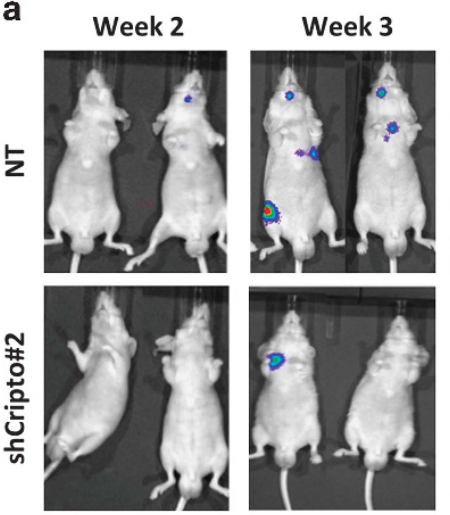

C

Total Number of Metastasis

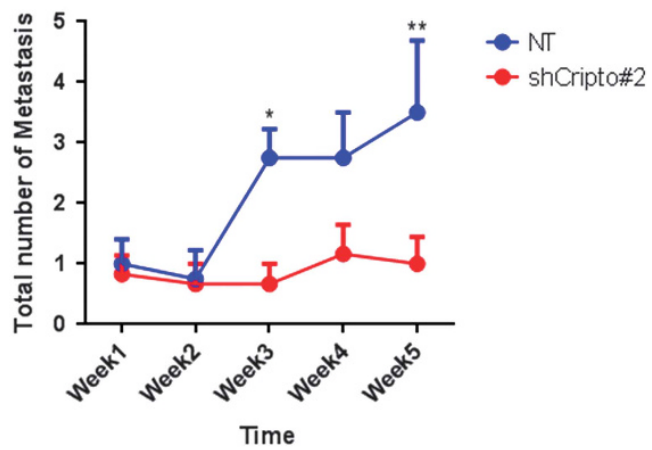

b

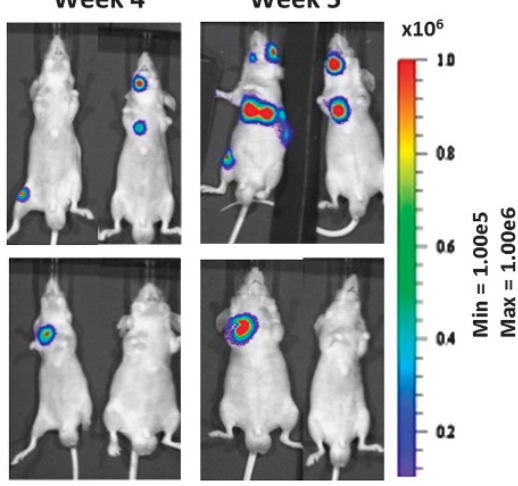

Tumor Burden

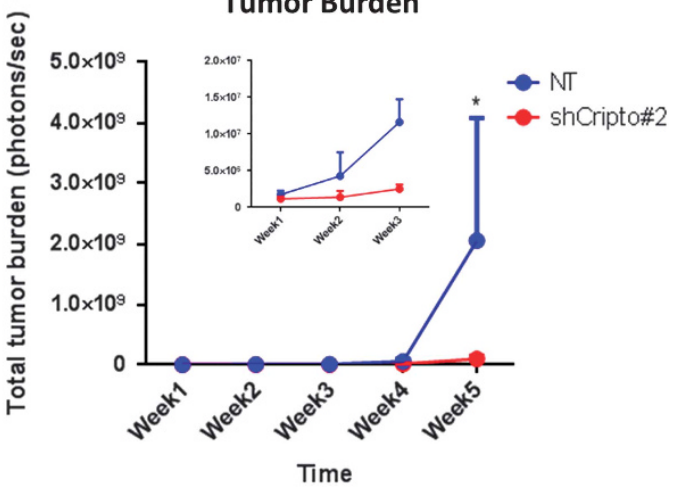

d

Total Number of Bone Metastasis

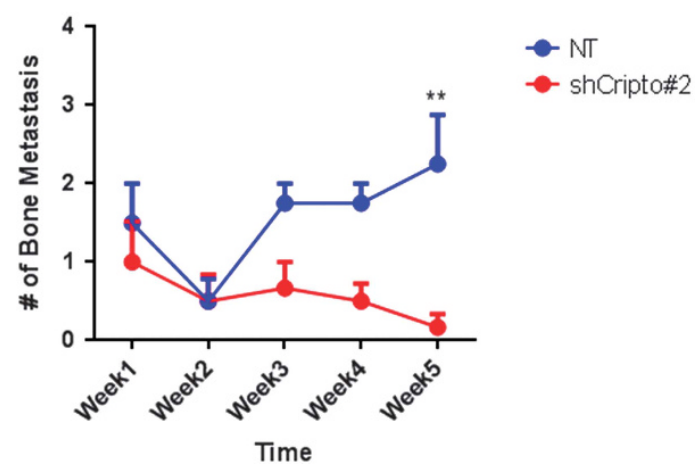

Figure 6. CRIPTO knockdown inhibits bone metastasis of human PCa cells in vivo. (a) PC-3M-Pro4Luc2 human PCa cells with CRIPTO knockdown (shCRIPTO no. 2) and shRNA scrambled control (NT) injected in the left ventricle of nude mice. Formation of distant growth was monitored weekly with bioluminescent imaging (BLI) measurements. Images are representative of six animals for CRIPTO knockdown and four animals for NT control. (b) Quantification of BLI measurements. Difference is significant at week $5(P<0.05$ with two-way analysis of variance (ANOVA)). CRIPTO knockdown is represented in red, and NT control is represented in blue. Error bars \pm s.e.m. (c) Total number of distant growths per mouse in mice injected with either CRIPTO knockdown (ShCRIPTO no. 2, red) or control (NT, blue) PC-3M-Pro4Luc2 cells $\left({ }^{*} P<0.05 ; * * P<0,01\right.$; with two-way ANOVA). Error bars \pm s.e.m. (d) Total number of distant growths (long bones, mandible, spine) per mouse in mice injected with either CRIPTO knockdown (ShCRIPTO no. 2, red) or control (NT, blue) PC-3M-Pro4Luc2 cells (**P<0.01; with two-way ANOVA). Error bars \pm s.e.m.

different components of the bone microenvironment in mechanistic detail.

Although PCa is manageable if detected early, the castrationresistant stage of the disease is associated with high morbidity and mortality because of bone metastases. Therefore, it is critical to identify and target pathways that contribute to the dissemination and generation of PCa bone micrometastases. In this study, we demonstrate that CRIPTO and its signaling mediator GRP78 may have pivotal, functional roles in the acquisition and maintenance of an invasive, metastatic phenotype in human prostate cancer (see schematic representation in Figure 7). Therefore, CRIPTO and GRP78 represent compelling molecules for targeting and monitoring highly aggressive stem/progenitorlike PCa cells to prevent the advancement of PCa towards the castration-resistant and metastatic stage.

\section{MATERIALS AND METHODS}

\section{Cell lines}

Human osteotropic PCa PC-3M-Pro4, ${ }^{13,29,33}$ C4-2B cells $^{34}$ and HEK293T cells ${ }^{35}$ were maintained as described previously. ${ }^{29}$ Human callus tissue from patients in good health was used to freshly isolate osteoblast precursor cells. Time to callus harvest ranged from 2 to 3 weeks. Indications for surgery were nascent (impending) malunion, failure of fixation or fractures that were operated on in a delayed manner. All fractures have subsequently successfully healed. Briefly, tissue was minced in a solution of $2 \mathrm{mg} / \mathrm{ml}$ collagenase (Millipore, Billerica, MA, USA) for $3 \mathrm{~h}$ at $37^{\circ} \mathrm{C}$ and vortexed every $30 \mathrm{~min}$ for $1-2 \mathrm{~min}$. The digested tissue was centrifuged for 5 min two times at 1000 r.p.m. (room temperature) in a media (Dulbecco's modified Eagle's medium, Glutamax MEM Non-Essential Amino Acids ( $1 \times$; Gibco-Thermo Scientific, Waltham, MA, USA), P/S). Pellet was resuspended in $0.25 \%$ Trypsin solution (Invitrogen, Waltham, MA, USA) for $1 \mathrm{~h}$ at $37^{\circ} \mathrm{C}$. The digested tissue was centrifuged at 1000 r.p.m. for $5 \mathrm{~min}$ in media. The cells were plated in osteoblast precursor media (Dulbecco's modified Eagle's medium with 10\% fetal calf serum, 1\% penicillin-streptomycin and 1\% MEM Non-Essential Amino Acids; GibcoThermo Scientific), passaged $\sim 80 \%$ confluency and differentiated at confluence: ascorbic acid (50 mg/ml; Merck, Darmstadt, Germany) was added in Dulbecco's modified Eagle's medium with $10 \%$ fetal calf serum, $1 \%$ penicillin-streptomycin and 1\% MEM non-essential amino acids (Gibco-Thermo Scientific). Upon detection of nodules (day 11), the medium was supplemented with $\beta$-glycerolphosphate $(5 \mathrm{~mm}$; Sigma, St Louis, MO, USA) and $100 \mathrm{~nm}$ dexamethasone. After 3 weeks, cells were fixed with $4 \%$ paraformaldehyde and analyzed for osteogenesis with Alizarin Red staining (ICN Biomedicals, Santa Ana, CA, USA). ${ }^{36}$ CM was generated with incubation time of $48 \mathrm{~h}$, in the absence of serum to prevent alteration of downstream assays. Cells were maintained at $37^{\circ} \mathrm{C}$ with $5 \% \mathrm{CO}_{2}$.

Suppressing CRIPTO and GRP78 with shRNAs

shRNAi for CRIPTO-1 (TRCN004889, TRCN004890 and TRCN004891) and HSPA5 (TRCN231123, TRCN218611) were obtained from Sigma's MISSION library. Lentiviral infection and selection were performed as described previously. ${ }^{37}$ Scrambled shRNA (SHC002, NT or control) with the lack of homology for any mammalian mRNA sequence was used as control. 


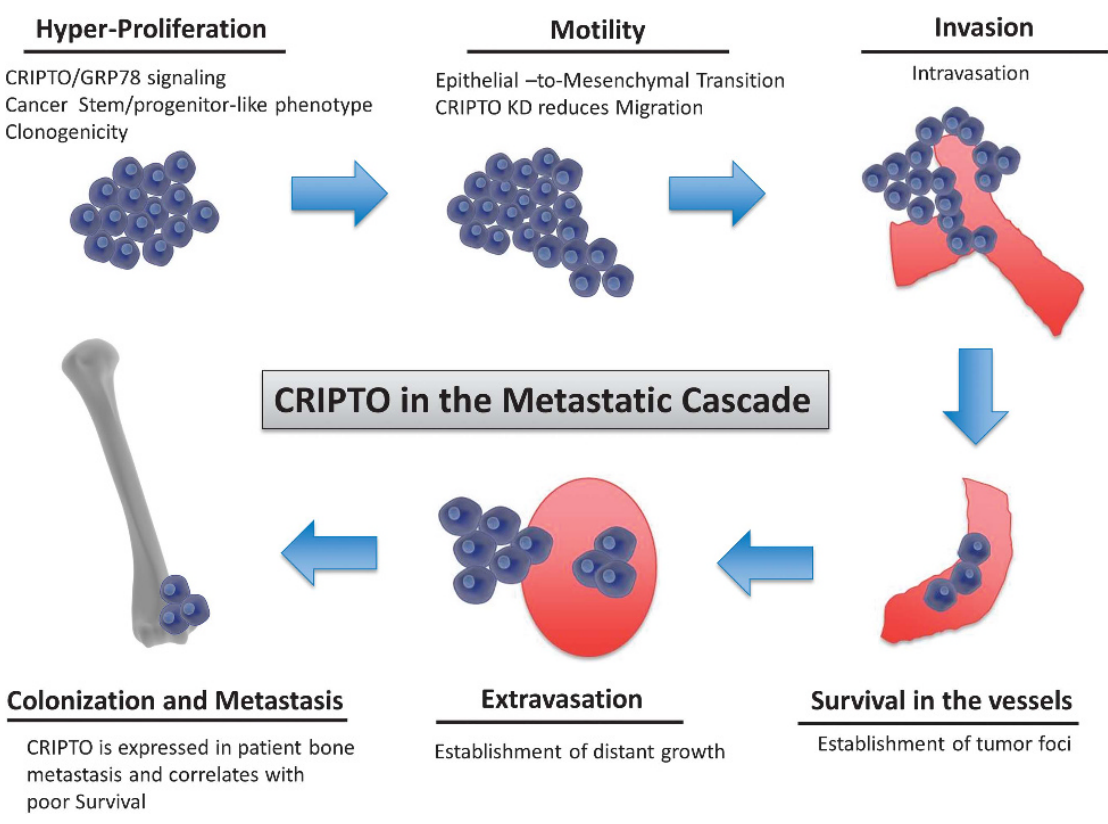

Figure 7. Schematic representation of the proposed role of CRIPTO in the metastatic cascade in human prostate cancer. CRIPTO and GRP78 influence cell proliferation and are highly expressed in highly metastatic stem/progenitor-like cells (ALDH ${ }^{\text {high }}$ ). CRIPTO and GRP78 knockdown impairs cell migration. CRIPTO- and GRP78-expressing cells are better adapted to surviving in the circulation and of forming distant metastases in zebrafish and mouse xenograft models.

\section{Suppressing CRIPTO expression with siRNAs}

Human CRIPTO siRNAs (SR304769A, SR304769B, SR304769C) and negative controls (SR30004, non-targeting NT) where purchased from OriGene Technologies (Rockville, MD, USA). PC-3M-Pro4-luc2 were transfected with a pool of three unique 27 mer siRNA duplexes (100 nm each) or (NT) control (300 nm) siRNA. Proliferation at different time points $(0,24,48$ and $72 \mathrm{~h})$ and migration were measured $48 \mathrm{~h}$ after transfection. Data are representative of four replicates.

Flow cytometry and aldehyde dehydrogenase assay

A total of 900000 PC-3M-Pro4Luc2 cells fluorescently labeled with PKH26 Red Fluorescent Cell Linker (Sigma-Aldrich, St Louis, MO, USA) were seeded in a $10 \mathrm{~cm}$ dish on a layer of confluent and differentiated human osteoblast. After $48 \mathrm{~h}$, cells were washed with phosphate-buffered saline (PBS), $1 \mathrm{~mm}$ EDTA and harvested using trypsin. Fluorescent PC-3MPro4Luc2 cells were separated from osteoblast with BD FACS ARIA (BD Biosciences, Franklin Lakes, NJ, USA). Non-labeled PC-3M-Pro4Luc2 cells, labeled PC-3M-Pro4Luc2 tumor-only and osteoblast-only cells were included as controls. Aldehyde dehydrogenase (ALDH) activity was measured using ALDEFLUOR Kit (StemCell Technologies, Durham, NC, USA). ${ }^{12}$ For knockdown validation, cells were harvested and incubated with CRIPTO antibody (FAB2772P, clone no. 89633, hCR-1-PE; R\&D, Minneapolis, MN, USA) as per the manufacturer's protocol. Data were analyzed with FCS Express Software (De Novo Software, Los Angeles, CA, USA).

\section{Western blot}

Proteins were extracted with RIPA buffer and quantified using Pierce Protein Quantification Assay (ThermoFisher Scientific, Waltham, MA, USA). Ten micrograms of samples were separated by $10 \%$ sodium dodecyl sulfate-polyacrylamide gel electrophoresis and transferred to a blotting membrane using standard techniques. Signal was detected after incubation with 1:1000 primary antibody (anti-CRIPTO, clone no. PBL6900; Spike et al. $^{31}$ ) and with 1:10000 secondary horseradish peroxidase antibody (Promega, Madison, WI, USA).

\section{CRIPTO overexpression}

CRIPTO construct, generated as described previously, ${ }^{23}$ was transfected in PC-3M-Pro4Luc2 and C4-2B cells with Lipofectamine 2000 (Life Technologies, Waltham, MA, USA) or with Fugene HD (Promega), respectively, according to the supplier's protocol. Data are representative of at least two independent experiments.

RNA isolation and real-time quantitative PCR

Total RNA was isolated with Trizol Reagent (Invitrogen) and CDNA was synthesized by reverse transcription (Promega) according to the protocol. qRT-PCR was performed with Bio-Rad CFX96 (Bio-Rad, Hercules, CA, USA). Gene expression was normalized to glyceraldehyde-3-phosphate dehydrogenase, hypoxanthine-guanine phosphoribosyltransferase and actin. Primers are listed in Supplementary Table 1.

\section{Luciferase reporter assay}

A total of 10000 PC-3M-Pro4 cells were seeded in a 24-well plate and Lipofectamine 2000 (Invitrogen) was used according to the manufacturer's protocol. Hundred nanograms of CAGA-Luc (TGF- $\beta$ reporter ${ }^{38}$ ) and $10 \mathrm{ng}$ of CAGGS-Renilla were transfected in combination of CRIPTO overexpression (100 ng construct per well) $24 \mathrm{~h}$ before assessment of Luciferase. Firefly and Renilla luciferase were measured with Dual Luciferase Assay (Promega). Data are shown as relative light units and representative of at least two independent experiments. Firefly luciferase is normalized for Renilla luciferase.

\section{Proliferation assay}

Cells were seeded at density of 1500 cells per well and allowed to grow for 24, 48 and $72 \mathrm{~h}$. Proliferation was assessed with 3-(4,5 dimethylthiazol-2yl)-5-(3-carboxymethoxyphenyl)-2-(4-sulfophenyl)-2H-tetrazolium after $2 \mathrm{~h}$ incubation at $37^{\circ} \mathrm{C}$ (CellTiter96 Aqueous Assay; Promega). Data were normalized for the number of cells. $N=5$ per condition, performed in duplicate experiments.

Transwell migration assay

Migration assays were performed using transwells $(8 \mathrm{~mm}$; Corning LifeSciences, New York, NY, USA). ${ }^{13}$ For the experiments with CM from osteoblast, this was diluted in the lower chamber 1:2 with medium $(50 \%$ condition) or administered undiluted (100\% condition). Data are representative of at least two independent experiments, respectively. 


\section{Colony formation assay}

A total of 100 cells were seeded in $2 \mathrm{ml}$ of medium supplemented with $10 \%$ FCII. After 2 weeks, cells were fixed with $4 \%$ paraformaldehyde, colonies stained with $0.1 \%$ crystal violet (Sigma-Aldrich) and quantified. ${ }^{39}$ Data are representative of at least three independent experiments.

\section{Zebrafish maintenance, embryo preparation and tumor cell} inoculation

$\operatorname{Tg}$ (fli1:GFP)i114 zebrafish line $e^{40,41}$ was handled and maintained according to local animal welfare regulations to standard protocols (http: //www.ZFIN.org). Two days postfertilization, dechorionized zebrafish embryos were anesthetized and injected with PC-3M-Pro4Luc2 cells fluorescently labeled as described previously. ${ }^{13,42}$ Quantification of the data was strictly standardized (automated pixel count of high-resolution images; criteria for quantification of extravasation are $>3$ cells extravasating per embryo). Zebrafish embryos (including nonimplanted controls) were maintained at $33^{\circ} \mathrm{C}$, to compromise between the optimal temperature requirements for fish and mammalian cells. ${ }^{43}$ Data are representative of at least two independent and blind experiments with $\geqslant 30$ embryos per group. Experiments with survival rate of control group lower than $80 \%$ were discarded.

\section{Mice}

Male 4-5-week-old athymic nude mice (Balb/c nu/nu $n=10$ per group) purchased from Charles River (L'Arbresle, France) were housed in ventilated cages under sterile condition and sterile food and water provided ad libitum. As animals were not treated with any drug, randomoization was not necessary after cell inoculation. Inoculation of cells was not done blind. Animal experiment has been approved by the local committee for animal health ethics and research of Leiden University (DEC no. 14226) and carried out in accordance with the European Communities Council Directive 86/609/EEC.

\section{Intracardiac PCa cell injection and whole-body bioluminescent imaging}

A single-cell suspension $\left(1 \times 10^{5}\right.$ PC-3M-Pro4Luc2 CRIPTO knockdown or NT control cells per $100 \mu \mathrm{l}$ PBS) was injected into the left ventricle of anesthetized 5-week-old male nude mice (Balb/c nu/nu). Tumor growth and metastasis formation was monitored weekly by bioluminescent imaging using IVIS100 Imaging System (Caliper LifeSciences, Waltham, MA, USA). ${ }^{12}$ Analyses of images was performed and quantified with Living Image 4.2 (Caliper LifeSciences).

\section{Immunohistochemistry}

Five micrometers of formalin-fixed, paraffin-embedded sections were dewaxed and rehydrated using xylene and ethanol, and endogenous peroxidase was blocked for $20 \mathrm{~min}$ in $0.3 \% \mathrm{H}_{2} \mathrm{O}_{2}$ in PBS. Heat-induced antigen retrieval was carried out in TRIS-EDTA buffer $(\mathrm{pH}=9$, 4397-9001; Klinipath, Duiven, The Netherlands) with a pressure cooker (1.2 bar). Antibodies (anti-CRIPTO, no. PBL6900; ${ }^{31}$ anti-cytokeratin-18, clone DC10; Dako, Santa Clara, CA, USA) were diluted 1:2000 in PBS-BSA 0.1\% and incubated overnight at $4{ }^{\circ} \mathrm{C}$. Envision (K500711; Dako) was used to visualize the antibody, followed by counterstaining with hematoxylin.

\section{Human material}

Clinical prostate cancer bone metastases (10 patients) were collected by the Erasmus MC Tissue Bank under ISO 15189:2007 standard operating procedures and used according to the Human Tissue and Medical Research Code for responsible use (2011). For human callus tissue (source of osteoblast) approval of the Institutional Review Board was obtained and confirmation that the Medical Research Involving Human Subjects Act (WMO) does not apply to the present study was obtained by the local ethics committee since the research was performed on 'waste material' (three patients) collected from Academisch Medisch Centrum (Amsterdam, The Netherlands).

\section{Statistical analysis}

Statistical analysis was performed with GraphPad Prism 6.0 (GraphPad software, La Jolla, CA, USA) using two-tailed unpaired $t$-test or analysis of variance for comparison between more groups. F-test was used to compare variances and standard deviations between the groups compared to meet the assumption of the statistical test. Data are presented as mean \pm s.e.m. $P$-values $\leqslant 0.05$ were considered to be statistically significant $\left({ }^{*} P<0.05,{ }^{* *} P<0.01\right.$ and $\left.{ }^{* * *} P<0.001\right)$.

\section{CONFLICT OF INTEREST}

The authors declare no conflict of interest.

\section{ACKNOWLEDGEMENTS}

We thank Tim Rodenburg and Janine Melsen (Department of Urology, LUMC) for technical support and Dr Boudewijn PT Kruithof (Department of Molecular Cell Biology, LUMC) for technical support and critical reading of the manuscript, Guido de Roo from the Flow cytometry facility (Department of Hematology, LUMC) and Jan Kroon (Department of Urology, LUMC) for providing experimental metastases. This research received funding from: FP7 Marie Curie ITN, Grant No. 264817-BONE-NET (to GvdP, EZ, ZG); Dutch Cancer Society, Grant No. UL2015-7599 KWF (to MK-dJ, GvdP, PK); Leiden University Fond (to MK-dJ) and Clayton Foundation for Biomedical Research (to PCG).

\section{REFERENCES}

1 Jemal A, Center MM, DeSantis C, Ward EM. Global patterns of cancer incidence and mortality rates and trends. Cancer Epidemiol Biomarkers Prev 2010; 19: 1893-1907.

2 Klauzinska M, Castro NP, Rangel MC, Spike BT, Gray PC, Bertolette D et al. The multifaceted role of the embryonic gene Cripto-1 in cancer, stem cells and epithelial-mesenchymal transition. Semin Cancer Biol 2014; 29: 51-58.

3 de Castro NP, Rangel MC, Nagaoka T, Salomon DS, Bianco C. Cripto-1: an embryonic gene that promotes tumorigenesis. Fut Oncol 2010; 6: 1127-1142.

4 Castro NP, Fedorova-Abrams ND, Merchant AS, Rangel MC, Nagaoka T, Karasawa $\mathrm{H}$ et al. Cripto-1 as a novel therapeutic target for triple negative breast cancer. Oncotarget 2015; 6: 11910-11929.

5 Lawrence MG, Margaryan NV, Loessner D, Collins A, Kerr KM, Turner M et al. Reactivation of embryonic nodal signaling is associated with tumor progression and promotes the growth of prostate cancer cells. Prostate 2011; 71: 1198-1209.

6 Terry S, El-Sayed IY, Destouches D, Maille P, Nicolaiew N, Ploussard G et al. CRIPTO overexpression promotes mesenchymal differentiation in prostate carcinoma cells through parallel regulation of AKT and FGFR activities. Oncotarget 2015; 6: 11994-12008.

7 Pilli VS, Gupta K, Kotha BP, Aradhyam GK. Snail-mediated Cripto-1 repression regulates the cell cycle and epithelial-mesenchymal transition-related gene expression. FEBS Lett 2015; 589: 1249-1256.

8 Shani G, Fischer WH, Justice NJ, Kelber JA, Vale W, Gray PC. GRP78 and Cripto form a complex at the cell surface and collaborate to inhibit transforming growth factor beta signaling and enhance cell growth. Mol Cell Biol 2008; 28: 666-677.

9 Lee AS. GRP78 induction in cancer: therapeutic and prognostic implications. Cancer Res 2007; 67: 3496-3499.

10 Kelber JA, Panopoulos AD, Shani G, Booker EC, Belmonte JC, Vale WW et al. Blockade of Cripto binding to cell surface GRP78 inhibits oncogenic Cripto signaling via MAPK/PI3K and Smad2/3 pathways. Oncogene 2009; 28: 2324-2336.

11 Pootrakul L, Datar RH, Shi SR, Cai J, Hawes D, Groshen SG et al. Expression of stress response protein Grp78 is associated with the development of castration-resistant prostate cancer. Clin Cancer Res 2006; 12(Part 1): 5987-5993.

12 van den Hoogen C, van der Horst G, Cheung H, Buijs JT, Lippitt JM, GuzmanRamirez $\mathrm{N}$ et al. High aldehyde dehydrogenase activity identifies tumor-initiating and metastasis-initiating cells in human prostate cancer. Cancer Res 2010; 70: 5163-5173.

13 Zoni E, van der Horst G, van de Merbel AF, Chen L, Rane JK, Pelger RC et al. miR-25 modulates invasiveness and dissemination of human prostate cancer cells via regulation of alphav- and alpha6-integrin expression. Cancer Res 2015; 75 : 2326-2336.

14 Bianco C, Strizzi L, Normanno N, Khan N, Salomon DS. Cripto-1: an oncofetal gene with many faces. Curr Top Dev Biol 2005; 67: 85-133.

15 Taylor BS, Schultz N, Hieronymus H, Gopalan A, Xiao Y, Carver BS et al. Integrative genomic profiling of human prostate cancer. Cancer Cell 2010; 18: 11-22.

16 Nakagawa T, Kollmeyer TM, Morlan BW, Anderson SK, Bergstralh EJ, Davis BJ et al. A tissue biomarker panel predicting systemic progression after PSA recurrence post-definitive prostate cancer therapy. PLoS One 2008; 3: e2318.

17 Ramaswamy S, Ross KN, Lander ES, Golub TR. A molecular signature of metastasis in primary solid tumors. Nat Genet 2003; 33: 49-54.

18 Chandran UR, Ma C, Dhir R, Bisceglia M, Lyons-Weiler M, Liang W et al. Gene expression profiles of prostate cancer reveal involvement of multiple molecular pathways in the metastatic process. BMC Cancer 2007; 7: 64. 
19 Morhayim J, van de Peppel J, Demmers JA, Kocer G, Nigg AL, van Driel M et al. Proteomic signatures of extracellular vesicles secreted by nonmineralizing and mineralizing human osteoblasts and stimulation of tumor cell growth. FASEB $J$ 2015; 29: 274-285.

20 Coleman RE. Clinical features of metastatic bone disease and risk of skeletal morbidity. Clin Cancer Res 2006; 12(Part 2): 6243 s-626249.

21 Shiozawa Y, Pedersen EA, Havens AM, Jung Y, Mishra A, Joseph J et al. Human prostate cancer metastases target the hematopoietic stem cell niche to establish footholds in mouse bone marrow. J Clin Invest 2011; 121: 1298-1312.

22 Saloman DS, Bianco C, Ebert AD, Khan NI, De Santis M, Normanno N et al. The EGF-CFC family: novel epidermal growth factor-related proteins in development and cancer. Endocr Relat Cancer 2000; 7: 199-226.

23 Gray PC, Shani G, Aung K, Kelber J, Vale W. Cripto binds transforming growth factor beta (TGF-beta) and inhibits TGF-beta signaling. Mol Cell Biol 2006; 26: 9268-9278.

24 Nagaoka T, Karasawa H, Castro NP, Rangel MC, Salomon DS, Bianco C. An evolving web of signaling networks regulated by Cripto-1. Growth Factors 2012; 30: 13-21.

25 Gray PC, Vale W. Cripto/GRP78 modulation of the TGF-beta pathway in development and oncogenesis. FEBS Lett 2012; 586: 1836-1845.

26 Ghotra VP, He S, van der Horst G, Nijhoff S, de Bont H, Lekkerkerker A et al. SYK is a candidate kinase target for the treatment of advanced prostate cancer. Cancer Res 2015; 75: 230-240.

27 Isogai S, Lawson ND, Torrealday S, Horiguchi M, Weinstein BM. Angiogenic network formation in the developing vertebrate trunk. Development 2003; 130: 5281-5290.

28 van der Pluijm G. Epithelial plasticity, cancer stem cells and bone metastasis formation. Bone 2011; 48: 37-43.

29 Kroon J, in 't Veld LS, Buijs JT, Cheung H, van der Horst G, van der Pluijm G. Glycogen synthase kinase-3beta inhibition depletes the population of prostate cancer stem/progenitor-like cells and attenuates metastatic growth. Oncotarget 2014; 5: 8986-8994.

30 Malanchi I, Santamaria-Martinez A, Susanto E, Peng H, Lehr HA, Delaloye JF et al. Interactions between cancer stem cells and their niche govern metastatic colonization. Nature 2012; 481: 85-89.

31 Spike BT, Kelber JA, Booker E, Kalathur M, Rodewald R, Lipianskaya J et al. CRIPTO/ GRP78 signaling maintains fetal and adult mammary stem cells ex vivo. Stem Cell Rep 2014; 2: 427-439.

32 Ozdemir BC, Hensel J, Secondini C, Wetterwald A, Schwaninger R, Fleischmann A et al. The molecular signature of the stroma response in prostate cancer-induced osteoblastic bone metastasis highlights expansion of hematopoietic and prostate epithelial stem cell niches. PLoS One 2014; 9: e114530.

33 Pettaway CA, Pathak S, Greene G, Ramirez E, Wilson MR, Killion JJ et al. Selection of highly metastatic variants of different human prostatic carcinomas using orthotopic implantation in nude mice. Clin Cancer Res 1996; 2: 1627-1636.
34 Thalmann GN, Anezinis PE, Chang SM, Zhau HE, Kim EE, Hopwood VL et al. Androgen-independent cancer progression and bone metastasis in the LNCaP model of human prostate cancer. Cancer Res 1994; 54: 2577-2581.

35 Graham FL, Smiley J, Russell WC, Nairn R. Characteristics of a human cell line transformed by DNA from human adenovirus type 5. J Gen Virol 1977; 36: 59-74.

36 van der Horst G, Farih-Sips H, Lowik CW, Karperien M. Hedgehog stimulates only osteoblastic differentiation of undifferentiated KS483 cells. Bone 2003; 33: 899-910.

37 van den Hoogen C, van der Horst G, Cheung H, Buijs JT, Pelger RC, van der Pluijm G. Integrin alphav expression is required for the acquisition of a metastatic stem/progenitor cell phenotype in human prostate cancer. Am J Pathol 2011; 179: 2559-2568.

38 Dennler S, Itoh S, Vivien D, ten Dijke P, Huet S, Gauthier JM. Direct binding of Smad3 and Smad4 to critical TGF beta-inducible elements in the promoter of human plasminogen activator inhibitor-type 1 gene. EMBO J 1998; 17: 3091-3100.

39 Guzman C, Bagga M, Kaur A, Westermarck J, Abankwa D. ColonyArea: an ImageJ plugin to automatically quantify colony formation in clonogenic assays. PLoS One 2014; 9: e92444.

40 Stoletov K, Montel V, Lester RD, Gonias SL, Klemke R. High-resolution imaging of the dynamic tumor cell vascular interface in transparent zebrafish. Proc Natl Acad Sci USA 2007; 104: 17406-17411.

41 Lawson ND, Weinstein BM. In vivo imaging of embryonic vascular development using transgenic zebrafish. Dev Biol 2002; 248: 307-318.

42 He S, Lamers GE, Beenakker JW, Cui C, Ghotra VP, Danen EH et al. Neutrophilmediated experimental metastasis is enhanced by VEGFR inhibition in a zebrafish xenograft model. J Pathol 2012; 227: 431-445.

43 Haldi M, Ton C, Seng WL, McGrath P. Human melanoma cells transplanted into zebrafish proliferate, migrate, produce melanin, form masses and stimulate angiogenesis in zebrafish. Angiogenesis 2006; 9: 139-151.

44 Karkampouna S, Kruithof BP, Kloen P, Obdeijn MC, van der Laan AM, Tanke HJ et al. Novel ex vivo culture method for the study of Dupuytren's disease: effects of TGFbeta type 1 receptor modulation by antisense oligonucleotides. Mol Ther Nucleic Acids 2014; 3: e142.

(c) (1) $\ominus$ This work is licensed under a Creative Commons AttributionC. NonCommercial-NoDerivs 4.0 International License. The images or other third party material in this article are included in the article's Creative Commons license, unless indicated otherwise in the credit line; if the material is not included under the Creative Commons license, users will need to obtain permission from the license holder to reproduce the material. To view a copy of this license, visit http:// creativecommons.org/licenses/by-nc-nd/4.0/

(c) The Author(s) 2017

Supplementary Information accompanies this paper on the Oncogene website (http://www.nature.com/onc) 